\title{
Why Realists Need Tropes
}

\author{
Markku Keinänen (University of Helsinki) \\ Jani Hakkarainen (University of Tampere) \\ Antti Keskinen (University of Tampere)
}

Corresponding author: Markku Keinänen

mkeina@utu.fi

Address:

PL 24 (Unioninkatu 40 A, 6. krs)

00014 Helsingin yliopisto

fax: 0294128060

tel: +358442987250 


\begin{abstract}
We argue that if one wishes to be a realist, one should adopt a realist ontology involving tropes instead of a Russellian ontology of property universals and objects. Either Russellian realists should adopt relata-specific relational tropes of instantiation instead of facts, or, better, convert to Neo-Aristotelian realism with monadic tropes. Regarding Neo-Aristotelian realism, we have two novel points why it fares better than Russellian realism. (1) Instantiation of property universals by tropes, and characterisation or inherence between tropes and objects, are more transparent ontological notions than relational inherence, which is assumed in Russellian realism with the relational tropes of instantiation. (2) Neo-Aristotelian realism makes better sense about abstract universals, which are a more viable option than concrete universals.
\end{abstract}

keywords: metaphysics, ontology, realism, universals, tropes

\title{
1. Introduction
}

Let us call "mainstream realism" any realist view about universals which subscribes to two general claims: first, there cannot be uninstantiated universals; second, in addition to universals, there is also some irreducible category of particulars that instantiate these universals. ${ }^{1}$ In the present article, we argue that mainstream realists need to introduce property or relation tropes in order to account for the instantiations of property universals. Moreover, we argue that the best currently available forms of mainstream realism introduce property tropes as instances of monadic universals.

By the qualification mainstream realism, we rule out two different types of realist position. First, we do not take up "Platonic realism", which allows for the possibility of

\footnotetext{
${ }^{1}$ For the sake of the argument, in this paper we follow the contemporary realist's way of drawing the distinction between universals and particulars. Universals can be instantiated, whereas particulars cannot have instances. See, e.g., Lowe $(2006,89)$.
} 
uninstantiated universals. Hence, we consider only "Aristotelian" immanent realist views, on which universals generically depend for their existence upon their particular instances. Second, we do not consider "bundle theories", which attempt to analyse individual objects (or, substances) as bundles of property universals. Bundle theories are forms of immanent realism but have a serious prima facie difficulty of explaining of how there can be two distinct objects (considered as bundles of universals) with exactly the same monadic properties. Although different versions of bundle theory have been proposed to solve this problem, we will not go into the debate of assessing the merits of these proposals. ${ }^{2}$ Similarly, since Platonic realism is not a commonly held metaphysical position on universals at the moment, we concentrate on Aristotelian (immanent) realism in the present article. ${ }^{3}$

Among the different forms of (mainstream) immanent realism, there are two mutually orthogonal distinctions. ${ }^{4}$ First, E. J. Lowe (2006, 98-99) divides immanent realism into two types, 'strong' and 'weak', depending on how the immanence of universals 'in' their particular instances is understood. According to strong immanent realism (Lowe 1998, 156; cf. 2006, 9899), universals are literally in their concrete instances, hence themselves concrete, that is, spatio-temporal (e.g. Smith 1997). By contrast, weak immanent realism maintains that universals are abstract, that is, non-spatio-temporal (Bergmann 1967, 49; Ellis 2001, 73-76; Lowe 2006, 99).

The second distinction, between the Russellian and the Neo-Aristotelian (immanent) realism concerns the very nature of instantiation. Russellians consider property universals as directly instantiated by objects or bare particulars, whereas Neo-Aristotelians believe that property universals are instantiated by tropes or modes (particular properties), which in turn characterise objects. ${ }^{5}$ Hence, Neo-Aristotelians (Smith 1997; Lowe 1998, 2006, 2009; Ellis

\footnotetext{
${ }^{2}$ Among the recent defences of (different forms of) bundle theory are Van Cleve (1985), Paul (2002), RodriguezPereyra (2004).

${ }^{3}$ Cf. Berman (2008) and Tugby (2013) for recent defenses of Platonic realism.

${ }^{4}$ In what follows, since we concentrate on mainstream realism, we will leave out the qualification.

${ }^{5}$ Lowe prefers "mode" to "trope" as he thinks that particular properties are objects' ways of being, which is not true of tropes in every trope theory $(1998,78 ; 2006,14-15)$. Nevertheless, henceforth we will use only "trope". When instantiation in the Neo-Aristotelian framework is discussed, the categorial difference between tropes and modes is not relevant.
} 
2001) account for the instantiations of universals by means of tropes but all prominent Russellians have rejected the existence of tropes.

Most Russellian realists are factualists (e.g., Bergmann 1967; Hochberg 1978; Armstrong 1997). Factualists identify the instantiations of universals with complex particulars belonging to a further ontological category, facts (states of affairs). In section 2, we argue that the factualist account of the instantiations of property universals fails. Factualists are unable to specify any intrinsic feature of facts on the basis of which one could consider facts as unities and distinct from mere sums of their constituents. In order to show how this difficulty can be overcome, we propose a new variant of Russellian realism that replaces facts as connecting entities with simple particulars, relational tropes of instantiation.

We argue that the introduction of relational tropes of instantiation amounts to a significant improvement of Russellian realism. However, the instantiations of property universals by concrete objects are themselves concrete, as we argue in section 3. By contrast, the best available theories of universals consider universals as abstract. Since universals are, according to Russellian realism, constituents of their concrete instantiations, this metaphysical view is left with the difficult problem of explaining how abstract universals can be constituents of their concrete instantiations. In section 4, we argue that the best answer to these difficulties is to adopt the Neo-Aristotelian account of instantiations of properties as property tropes which stand in a single formal relation of instantiation to abstract property universals.

\section{Factualism}

The current versions of Russellian realism introduce objects or bare particulars and property universals, and possibly 'ties' or 'nexus', but reject tropes. Property universals are directly instantiated or exemplified by objects or bare particulars. Russellians take the relation of instantiation or exemplification as either primitive or grounded. On the latter option, one may distinguish two forms of Russellian realism, the dual-constituent and the triple-constituent 
view. The dual-constituent version explains instantiation by reference to the existence of an entity over and above objects and universals: a fact. Both facts and objects are concrete, but universals are considered either as abstract or concrete. It is sufficient here to focus on atomic facts that are considered as complex entities, which are constituted by object $a$ and property universal $F$ whenever $a$ instantiates $F{ }^{6}$

To this scheme, Bergmann (1967, 11, 14, 22-23, 44-45), Hochberg (1978, 339) and J.P. Moreland (2001, ch.5) add another universal, the fundamental tie or nexus of exemplification. ${ }^{7}$ Its theoretical role is to connect a bare particular and a universal property in a fact. On this triple-constituent factualism, the entity instantiating the property is thus a bare particular, a bare individuator, not an ordinary object. Bergmann, Hochberg and Moreland think that ordinary objects are complex facts constituted by the instantiations of monadic properties by a bare particular. An atomic fact consists in a bare particular instantiating a monadic property universal. On this view, both ordinary objects and their constituent atomic facts are particulars.

The proposed versions of Russellian realism are partly motivated by solving a version of the problem generally known as Bradley's relation regress (cf. Bradley 1897, 18). Assume that object $a$ has a property $F$ contingently, which means that $a$ and $F$ (and tie $E$ ) can exist without being connected to each other ( $a$ could be not- $F$ ). From this, it seems to follow that there has to be an ontological ground for $a$ instantiating $F$; the mere co-existence of $a$ and $F$ is not sufficient for $a$ instantiating $F$. This ground is that $a$ and $F$ (and $E$ ) are connected by a third entity: the relation of first-order instantiation that connects $a$ and $F$ (and $E$ ). But now we face another call for explanation: what is the ontological ground for the fact that $a$ and $F$ (and $E$ ) are connected by the relation of first-order instantiation? In order to account for that, we must introduce a three-place (four-place) instantiation relation to connect instantiation and the

\footnotetext{
${ }^{6}$ The dual-constituent view is a modification of but not identical to Armstrong's ontology in 1997. If universals are abstract in the the dual-constituent view, one major difference is that Armstrong says that all universals are "far from removed from spacetime", which suggests that they are concrete (part of the space-time system) (Armstrong 1997, 40). By contrast, an advocate of weak immanent realism explicitly assumes that they are abstract. On both views, particulars, properties and relations must be constituents of some (but not any particular) fact (or, state of affairs) but facts are complex entities having exactly these constituents. Note that Armstrong's (2004) partial identity view of instantiation, which he rejected later, does not introduce facts in this sense. We do not discuss it since Armstrong himself abandoned it.

${ }^{7}$ Hochberg $(2009,103)$ changes his earlier view and replaces the nexus with compresence.
} 
entities it relates, namely, $a$ and $F$ (and $E$ ), and so on. Thus, in order to give an ontological ground for one instantiation, we must postulate an infinite number of instantiation relations (Armstrong 1997, sec. 8.12). This infinite regress is vicious since at no point do we reach an explanatory closure. Hence, we have not shown that it is possible that $a$ and $F$ (and $E$ ) are connected by the relation of instantiation.

Facts are entities designed to block Bradley's regress (cf., e.g., Bergmann 1967, 6-12; Armstrong 1997, sec. 8.12; Hochberg 1978, 336-340). The main idea is that the existence of a fact suffices to stop the regress before it gets started. The instantiation of $F$ by object or bare particular $a$ amounts to the existence of the fact that $F a$, which is a complex, third entity having these two constituents (e.g. Armstrong 1997, 20, 28-9). $F$ is instantiated by a because the fact Fa exists (Ibid.). In Bergmann's, and Hochberg's earlier, triple-constituent view, the tie of exemplification is a connector that can connect without itself being connected. Tie $E$ connects $a$ and $F$ without launching Bradley's regress because its connecting $a$ and $F$ amounts to the existence of the fact that $E$ ties $a$ and $F$. Both the dual-constituent and triple-constituent view are supposed to avoid Bradley's regress, since there is no need for a fourth or fifth entity (e.g., the relation of instantiation) that would ground instantiation. So factualism appears to be a promising way to avoid Bradley's regress. It seems that facts are, indeed, possible entities.

Still, the factualist's putative answer to Bradley's regress has been heavily criticized (Betti 2014, Dodd 1999, 155; MacBride 2011, 172; Maurin 2010, 2012; Vallicella 2002; Wieland \& Betti 2008). We will not repeat all these criticisms. Instead, we will concentrate on two problems pertaining to facts: the first is the unity-in-complexity problem, to explain why facts can be considered to form a unity. Why are they unities in contradistinction to aggregates of their constituents, which are pluralities? The second problem concerns the alleged category distinction between facts and other complex entities. What is the ontological ground of this category distinction? We will argue that as these problems do not have any clear solution, it is better to postulate simple particulars, the relational tropes of instantiation.

A fact is rigidly existentially dependent on its constituents since it could not exist without 
precisely those entities that are its constituents. ${ }^{8}$ By contrast, the existence of the fact is contingent relative to the existence of its constituents; the constituents do not depend rigidly for their existence on each other or the fact. So the constituents cannot account for the possibility or actuality of their being connected by the fact. The only entity in factualism that can do this ontological work is the fact itself, which is exactly what the factualists suppose it to do. According to factualism, when a fact exists, its constituents are, indeed, connected by the fact (on the dual-constituent view, $a$ does instantiate $F$ ) and the fact is a connecting entity that is an "addition of being" in comparison to its constituents.

Thus, fact $F a$ is stipulated to exist whenever $a$ instantiates $F$. It is a complex entity whose exact function is to connect $a$ and $F$, that is, to explain the instantiation of the property $F$ by the particular $a$. In this sense, facts are an ad hoc postulation - the primary reason to introduce facts is to account for the instantiations of Russellian universals by particulars and stop Bradley's regress. ${ }^{9}$ Since a similar complaint might be directed against the entities postulated in rival ontological category systems, this is perhaps not a fatal objection to factualism. However, our aim is to show that facts are a non-transparent ad hoc postulation.

According to factualism, facts not only connect their constituents (ground instantiation). They are also complex unities, single entities that have existing non-identical constituents (e.g. Armstrong 1997, 122; Hochberg 2009, 107). Accordingly, as Maurin argues, factualists face not only the problem of Bradley's regress but also the unity-in-complexity problem $(2012,801$ 2). ${ }^{10}$

\footnotetext{
${ }^{8}$ Cf. Simons (1987, 294-300) for the notions of rigid and generic dependence.

${ }^{9}$ One might claim that facts have independent semantic functions. First, facts are often claimed to be introduced as truthmakers of the true atomic truth-bearers (e.g., propositions) (cf. Armstrong 1997, ch.8). Second, one might suggest that true truth-bearers are in a correspondence relation to facts as certain correspondence theories of truth seem to maintain, cf. David 2013. However, unless we assume a close parallel between the structure of truthbearers and the structure of reality, neither of these functions can be considered as independent reasons to introduce facts. Rather, they are by-products of the alleged function to explain instantiations of Russellian universals.

10 Vallicella $(2002,18 \mathrm{ff}$.) also takes up a version of the unity problem with regard to facts and argues for the conclusion that facts as unities cannot exist independently of "external unifiers": factors external to facts which unify them. Nevertheless, he accepts two theses to which we will not subscribe. First, claiming that facts have certain constituents contradicts the contention that they are entities additional to the plurality of their constituents. Second, we contest the claim that Armstrong's truthmaker argument gives us strong reasons to maintain that there are facts as entities dependent on external unifiers. For one, we will argue that factualist claims are implausible
} 
In order to see if factualists can answer the unity-in-complexity problem, let us not suppose, for the sake of the argument, that facts are actual and hence possible as complex unities. But let us suppose that their constituents on the dual-constituent view are actual: there are objects and property universals (this is also true on the factualist assumption that there are facts). From this supposition, it follows that there are also aggregates (or pluralities) of objects and property universals such as the plurality of $a$ and $F$. As pluralities, these aggregates are not unities: they are not single entities over and above their members. If $a$ and $F$ exist, there need not be a third entity, namely, sum $a+F$, which would be an individual and hence a unity.

By contrast, according to factualism, when there is the fact $F a$, there is a third entity in addition to $a$ and $F$. If we assume both the existence of sum $a+F$ and fact $F a$, as Armstrong (1997, ch.8) does, there are two distinct entities having exactly the same essential constituents. While sum $a+F$ is also identical with the aggregate of its constituents, fact $F a$ is not. ${ }^{11}$ More generally, then, facts are categorially distinct from the sums of their constituents. By the same token, they are assumed to have a stronger unity than mere sums of their constituents - facts are assumed to connect their constituents in an instantiation of a universal by a particular. Hence, the factualist faces two difficult questions: first, why is it possible that facts are such distinct unities? What is the further factor besides the existence of the constituents that makes facts distinct unities? Second, what is the ontological ground of the categorial distinction between facts and aggregates of their constituents?

One proposed answer to the second question is to stipulate that this category distinction is a brute fact and that there cannot be any ontological explanation for it (cf. Hochberg 1978, 338). But if the distinctness is a brute fact, fact $F a$ is entirely distinct from plurality $F, a$ or sum $a+F$. The fact and the sum are assumed to have exactly the same constituents; yet they are

(conductive to non-transparent primitives and new serious problems) but not manifestly contradictory; for two, in order to account for the instantiations of properties, one need not postulate facts.

11 The claim that some aggregate of entities is identical with the entity the plurality composes is, of course, contestable and requires generalization of the notion of identity to hybrid cases, namely, to identities between aggregates of distinct individuals and individuals (cf. Noonan \& Curtis 2014: sec. 7). A weaker, and less contestable, claim would be that (at least in some cases) a plurality of certain entities composes a further entity, their mereological sum, and that the composition relation is analogous to the identity relation. Here, it suffices to point out that, unlike complex concrete particulars, facts are not identical with the mereological sums of their constituents. 
supposed to be entirely distinct entities that belong to distinct categories. Nevertheless, we cannot just stipulate that certain complexes are "facts", which beyond this are indistinguishable from complexes called "mereological sums". Unless this category distinction is based on some intrinsic factor in the entities introduced, we cannot bring any clarity to our ontological category system. Unless we can account for the unity of facts as contrasted with sums, it is of no help to just call certain complexes facts and claim that there is a primitive category distinction. ${ }^{12}$ Hence an adequate answer to the unity problem would lead to a successful elucidation of the categorial nature of facts as special kinds of complex entities.

As far as we know, the only proposed factualist attempt to elucidate the nature of facts as special kinds of complexes is in terms of "non-mereological mode of composition" (Armstrong 1997, 118ff). The idea is that the non-mereological mode of composition distinguishes facts as unities from the aggregates or, alternatively, the mereological sums of their constituents. The composition of facts is "non-mereological" because it does not obey the laws of classical extensional mereology. The crucial differences between facts and the "mereologically" constituted entities such as sums are, first, that two distinct facts may well be constituted by exactly the same constituents (mereological extensionality fails), and second, that the possible constituents of a fact may well fail to constitute a fact (the composition of facts is restricted). ${ }^{13}$

The whole idea of "non-mereological composition" rests on a negative characterisation of the composition of facts. As such, the talk about non-mereological composition specifies the mereological principles which do not hold in the case of facts but does not spell out why facts are distinct from mereological sums. Compare Armstrong's doctrine of non-mereological composition with the non-mereological conditions introduced for the parts of a complex object

\footnotetext{
12 Maurin (2012, 801-2) makes the controversial claim that categorial differences in more than one-category ontologies are brute and not explicable in terms of something else. However, she does observe that when two entities are "intimately related", e.g., by having the same essential constituents, as in the case of facts and mereological sums, their categorial difference cannot be brute.

13 Bergmann $(1967,9)$ does not accept the existence of mereological sums; according to him, "[a] collection of entities is as such itself not an entity". According to Bergmann, all complex entities are facts, which are built from simples by means of the tie(s) of exemplification.
} 
to spell out when they satisfy the conditions of a restricted composition. ${ }^{14}$ In both cases, the composition is restricted and hence "non-mereological". However, the metaphysicians discussing restricted composition of objects attempt to explain when composition can take place by recourse to some further facts. By contrast, for Armstrong, the occurrence of every instance of non-mereological composition is a brute fact which cannot be elucidated in terms of something else. It cannot be non-circularly explained in terms of a particular instantiating a universal. Facts and their "non-mereological composition" are supposed to account for the instantiations of universals but not vice versa. ${ }^{15}$ Hence, the existence of every new fact and the categorial distinction between mereological sums and facts is a brute fact.

Mereological sums are the best candidates for entities partially identical with their constituents. ${ }^{16}$ Since two distinct atomic facts can have exactly the same constituents, it does not make sense to speak about partial identity of facts with their constituents having the full identity as its limiting case. Hence, we cannot account for the co-location of a fact with its constituents or the rigid dependence of a fact on its constituents by means of partial identity. So, we should ask: is it reasonable to consider facts as complex entities at all, i.e., constituted by their alleged constituents?

Consider the following alternative. Instead of facts, the Russellian realist postulates relational tropes of instantiation accounting for each specific instantiation of a universal by a particular. Like facts, the relational tropes of instantiation would be particulars. More specifically, they would be tropes, the assumption of which would violate the claim that all properties and relations are universals. However, relational tropes of instantiation would be introduced for exactly the same ontological work as facts. They would account for the instantiations of universals by particulars. An instantiation trope would be relata specific in the

\footnotetext{
${ }^{14} \mathrm{Cf}$. van Inwagen (1990) and the resulting philosophical discussion of the different answers to van Inwagen's Special Composition Question.

15 Officially, Armstrong (1997, ch. 8) introduces facts (in his terms, states of affairs) to act as truthmakers of contingent propositions. However, their main ontological function is to account for the instantiation of Russellian universals by particulars. Moreover, the existence of every fact is a brute fact, i.e., not explainable in terms of something else.

${ }^{16}$ According to Armstrong (1997, 17-18), the constitution of complex particulars obeys the principles of classical extensional mereology and we can speak of the partial identity of complex particulars with their parts having identity (i.e., the sameness of parts) as its limiting case.
} 
following sense: its nature is to connect $a$ and $F$ by way of instantiation, its existence entails that it is rigidly dependent on $a$ and $F$ and it relationally inheres in them. Therefore the existence of instantiation trope $i$ entails that a certain universal $F$ is instantiated by a certain particular $a$. Nevertheless, relational tropes of instantiation would not have the further unexplainable features of facts such as their own special kind of composition and unity. As primitive entities, the relational tropes of instantiation do not have any kind of constituents. They are simple individuals and hence unities.

Considering facts as complex entities seems not to bring any ontological explanatory benefits for the Russellian realist. Or, to be more cautious, the (alleged) benefits related to the semantic correspondence intuition are overweighed by the deeply non-transparent nature of fact composition. On the other hand, considering "facts" as primitive connecting entities means the rejection of facts as complex entities. It amounts to the introduction of the relational tropes of instantiation described in the previous paragraph.

Consequently, our conclusion is that factualists have not been able to show that facts are possible, not to speak of their actuality. It would not do to insist that it is a starting point of factualism that there are facts as unities, constituted and connecting entities. This would put the cart before the horse. Rather, the Russellian realist can replace facts with relational tropes of instantiation. Rigid dependence and relational inherence would remain primitive but codified in the nature of a relational trope. After this simple move, the Russellian realist need not introduce such further primitives as "the non-mereological fact composition" and "fact existence". Since the resulting position introduces fewer different kinds of formal ontological relations than factualism without significant losses in explanatory benefits, the Russellian realist has strong reasons to adopt it. ${ }^{17}$

\footnotetext{
${ }^{17}$ Formal ontological relations characterise the general relations an entity bears as a member of an ontological category to distinct entities (of the same or other categories). For instance, they spell out how an entity can exist as a constituent of the world (existential dependencies) and how it exists as a constituent of the world (mereological relations). They are not further entities but rather constitute an important part of the description of the entities in a category system. For further discussion of formal ontological relations, see Smith \& Mulligan (1983), Lowe (2006, ch. 3), Correia \& Keller (2004) and the other articles in the same issue of Dialectica.
} 


\section{The Location Problem}

After having argued that the Russellian realist should reject facts, let us take stock. The version of Russellian realism suggested in the previous section is a thing ontology: the instantiations of universals are complex things closed under rigid dependence ${ }^{18}$, constituted by an n-adic universal, $\mathrm{n}+1$-adic relational trope of instantiation and $\mathrm{n}$ objects. Unlike facts, the instantiations are mereological sums of their constituents.

It is a widely known fact that relation universals or similar entities are not well suited to stop Bradley's relation regress as construed in contemporary discussions. ${ }^{19}$ The main reason for this is that relation universals are not relata specific: their existence does not entail that they connect (or relate) their specific relata. ${ }^{20}$ By contrast, the relata-specific relational tropes seem to stop the regress because we need not postulate any further relations to account for instantiations. Although we are not fully convinced of the relata-specific solution in its present form, it is clearly preferable to the factualist solution for the reasons spelled out in the previous section. One need not be a trope theorist to make use of this solution; the Russellian realist can make use of it as well. ${ }^{21}$

On the relational-trope version, instantiations are particulars. This leaves two further options: either they are concrete or abstract, that is, either localised or not localised in spacetime. The best empirical examples of monadic property universals are physical quantities (such as masses, electric charges and spin quantum numbers), which bestow causal powers on their

\footnotetext{
${ }^{18}$ Dependence closures with respect to rigid dependence are groups of entities whose rigid dependencies are satisfied inside the group. Arguably, they form rigidly independent existents, cf. Simons 1987, 322.

${ }^{19}$ Because of being universals and not being relata-specific, the fundamental ties of exemplification cannot stop the regress either (cf. Bergmann 1967, 9ff.)

${ }^{20}$ After introducing the notion, Wieland \& Betti $(2008,519)$ speculate about the possibility of considering universals as relata specific. Nevertheless, this would involve complications, which would be difficult to deal with such as the claim that necessarily, if a certain definite relation universal exists, certain definite objects exist and the universal relates these objects in different pairs (or triples, etc.) in a certain definite way.

${ }^{21}$ Dodd (1999, 153ff) has suggested avoiding Bradley's regress by taking instantiations as primitive predications without reifying instantiation as an existing relation or relating entity. Whatever its exact merits (e.g., in terms of avoidance of facts and necessary connections), the suggested answer fails to deal with Bradley's relation regress. It does not ground contingent instantiations of properties and relations by means of the existence of the entities involved. But then, because of the dialectical context, one has to show why Bradley's regress is not a substantial problem. In other words, one should argue why it is not a problem that there are brute contingent connections in the world.
} 
instances (cf., e.g., Ellis 2001, 115). The fact that these causal powers act in certain spatiotemporal locations constitutes a strong reason to maintain that also the instantiations of universals have a definite spatio-temporal location (that is, are concrete). More generally, assuming that there are universals instantiated by concrete particulars, the instantiations of universals enter into causal connections and are observed in the locations of these particulars. Therefore, also the instantiations of universals seem to be concrete. Assuming that the instantiations of universals are abstract like such alleged entities as sets, propositions and numbers would leave one with the difficult question why the instantiations of universals can differ from these other abstract entities by having effects in the spatio-temporal locations of concrete entities.

Thus, if Russellian universals are abstract, there appear to be concrete entities, concrete instantiations of universals that have abstract universals as their constituents. This violates the prima facie plausible claim that all constituents of concrete entities are themselves concrete. It is, at least, contestable whether non-spatio-temporal (abstract) entities and spatio-temporal (concrete) entities can constitute entities localised in space-time. ${ }^{22}$ This location problem is equally pressing for the factualist and the relational-trope versions of Russellian realism.

In attempt to answer the location problem, the Russellian realist might go on to maintain that, as parts of the space-time realm, all universals are concrete. Nevertheless, few metaphysicians have worked out this view in detail. ${ }^{23}$ As we have argued elsewhere [SELFREFERENCE OMITTED], perhaps the most detailed defence of the view due to Cody Gilmore (2003) falls into the trap of Lowe's $(1998,156 ; 2006,99)$ and Ehring's (2002) incoherence arguments against concrete universals. These arguments suffice to show that it is very difficult to make sense of the grounding of the locations of concrete universals. Hence, considering

\footnotetext{
${ }^{22}$ Parsons (2007, 205-6) defends the contention that hybrid entities constituted by abstract and concrete parts (if any) are exactly located in the locations of their concrete parts. He suspects that the intuition that such entities do not have exact location is based on "[a] temptation to treat objects not in space as if there were special place "not in space" in which those objects are spatially located". Be that as it may, it remains problematic whether such a hybrid entity can have a location determined as a function of the locations of its parts.

${ }^{23}$ Armstrong $(1989,1997)$ appears to maintain that, as constituents of the space-time realm, at least all monadic universals are concrete. But he does not elucidate how their locations are grounded: are universals in the basic spatio-temporal relations? Or do they obtain their locations derivatively, as constituents of spatio-temporally located entities?
} 
universals as concrete does not seem to be a live option.

No Russellian realist has been able to tackle the location problem. The only currently available coherent view about the location of universals is that universals are abstract, that is, do not have any spatio-temporal location. Hence, the realist must reconsider the relation between universals and their instances. In what follows, we argue that, in order to improve on her position, the realist should adopt tropes and Neo-Aristotelian property universals. The resulting view would cease to be a form of Russellian realism and would look very much like Neo-Aristotelian realism about properties.

\section{Neo-Aristotelian Abstract Universals}

According to Neo-Aristotelian Weak Immanent Realism, all property universals are abstract, but have tropes as their instances. Instead of relational tropes, the Neo-Aristotelian introduces monadic property tropes to account for instantiations of monadic properties. Instantiation is a primitive formal ontological relation that connects abstract property universals and their concrete instances: property tropes instantiate abstract property universals. ${ }^{24}$ By contrast, "instantiation" familiar from the Russellian context, i.e., individual objects instantiating property universals ("exemplification" in Lowe's terms), is analysed by means of two formal ontological relations, tropes instantiating property universals and tropes characterising objects (Lowe 2006, 40). The contingency of property exemplification is explained in terms of the contingency of the existence of tropes relative to the existence of the objects they characterise. As individual accidents, tropes are rigidly dependent on objects they characterise but the converse need not hold (Lowe 2006, 205 ff.).

Lowe's Neo-Aristotelian realism provides us with a more tenable account of the relationship between abstract universals and their concrete instantiations than Russellian

\footnotetext{
${ }^{24}$ Here, in characterising instantiation as a formal ontological relation connecting property (and substantial kind) universals and their instances, we follow Lowe (2006, ch. 3). Although being less explicit in detail, Ellis's (2001) view of the relation between property tropes and their kinds can be characterised in similar manner.
} 
realism. Instantiations (or, better, instances) of property universals are tropes. Universals must have instances in order to exist but they stand to their instances in exactly one primitive formal ontological relation: instantiation. Since instantiation is a primitive formal ontological relation, it holds necessarily given the existence of its relata. Since universals are not parts or constituents of their instances, the location problem does not arise.

Still, the Russellian might have two objections to Neo-Aristotelian realism. First, monadic property accidents bring with themselves suspicious rigid dependencies between property tropes and objects having these tropes. Are they not mysterious kinds of necessary connections between wholly distinct entities $?^{25}$ Second, according to Russellian realism, all properties are universals. By contrast, the Neo-Aristotelian introduces both property universals and tropes. Does this not mean ontological extravagance, commitment to unnecessary fundamental kinds of entities (cf. Armstrong 1978, 85-86)? Similarly, the Neo-Aristotelian introduces two different types of basic formal ontological relation (instantiation and characterisation) instead of just one (relational inherence). Does this not amount to a clear disadvantage in terms of ideological economy in comparison with the Russellian?

As regards the first objection, the Neo-Aristotelian postulates monadic property tropes in a formal relation of characterisation to objects. Property tropes with these formal features are introduced for certain ontological explanatory work, to account for the instantiations of universals. Rigid dependencies, which are entailed by this characterisation connection, get their justification from this explanatory work. As we argued in section 2, the Russellian realist should postulate relational tropes inhering in, and rigidly dependent on, two distinct entities. Relational inherence and multiple rigid dependence hold because the nature of the relational trope is to relate its specific relata in a specific manner (cf. Maurin 2002, 164 and Wieland \& Betti, 2008). With regard to monadic property tropes, the Neo-Aristotelian realist makes a parallel claim that it is the nature of a monadic trope to be a property of a certain definite object. Hence, the Russellian realist does not have any advantage over the Neo-Aristotelian in avoiding

${ }^{25}$ Cf. Armstrong's (1997, 116-117) criticism of "non-transferability" of the tropes C.B. Martin introduces. Since Martin's tropes are individual accidents of substances, the same criticism is probably supposed to apply to all individual accidents. 
necessary connections. Quite the contrary, instead of monadic inherence, she should invoke a more complicated formal relation of relational inherence for grounding instantiations of monadic universals.

The second objection does not fare well either. Assuming that the Russellian realist rejects facts, she needs to postulate basic entities that belong to three fundamental categories: objects, property universals and relational tropes. As complex things formed in accordance with certain ontological principles, relational complexes are entities of a derived category. In turn, the Neo-Aristotelian introduces objects, monadic tropes and property kind universals. Thus, there is no difference in the number of fundamental categories introduced to account for the exemplifications of property universals. ${ }^{26}$

Things become trickier when we compare these rival schemes in terms of the different primitive formal ontological relations. The Neo-Aristotelian needs two different types of primitive formal ontological relation (characterisation and instantiation) to account for the exemplifications of property universals. By contrast, the Russellian realist seems to be able to manage with relational inherence, which binds the relational tropes of instantiation to their relata. Nevertheless, as we pointed out above, relational inherence is a more complicated sort of formal ontological relation than monadic inherence (or, characterisation): it is supposed to bind relational tropes to two distinct relata. Monadic inherence binds property tropes to their bearers, which are co-located with the former. By contrast, at least in the special case of relational tropes of instantiation, relational inherence connects entities belonging to distinct categories (property universals and objects) into a single complex entity. In light of the location problem, spelling out how this is possible is extremely difficult as argued in section 3.

Hence, considerations pertaining to the number of primitive formal ontological relations does not shift the balance in favour of Russellian realism. First, monadic inherence is less complicated than relational inherence. Second, by introducing the formal relation of instantiation, the Neo-Aristotelian avoids making abstract universals constituents of concrete

\footnotetext{
${ }^{26}$ Contemporary Neo-Aristotelians do indeed postulate further fundamental categories for other explanatory purposes. An example is Lowe's $(2006 ; 2013)$ substantial kind universals. Whether these further postulations are needed is a separate issue.
} 
entities.

\section{Conclusion}

We have argued that all tenable forms of mainstream realism about universals need to introduce tropes in addition to property universals. More precisely, we have argued that Russellian realists need to assume tropes; ultimately, if they wish to retain realism, the best available option for them is to convert to Neo-Aristotelianism.

Facts have often been considered as the main contenders of property tropes. Most Russellian realists introduce facts to account for the instantiations of universals and to avoid Bradley's relation regress. In section 2, we argued that the suggested answer to Bradley's regress in terms of fact existence leads to two serious inter-related problems. The first is to give a satisfactory account of the category distinction between facts and the mereological sums of their constituents. The second is to answer the unity-in-complexity problem, to show that facts can be considered as existing single entities over and above aggregates of objects and property universals. We argued that factualists have not been able solve these problems as they have not managed to specify any intrinsic feature of facts that would account for their unity and the category distinction between facts and mereological sums.

However, the Russellian realist can replace facts with relational tropes of instantiation, which are primitive particulars accounting for the instantiations of universals. They share two crucial features with facts: they connect (or relate) certain definite entities (e.g., a certain monadic property and a certain particular) and are rigidly dependent on them. The resulting version of Russellian realism, described in section 3, makes Russellian property universals, objects and relational tropes of instantiation constituents of complex objects, relational complexes. While it avoids the difficulties pertaining to facts, the relational-trope version is still left with the location problem: how can property universals be abstract (as they are on any 
plausible conception available), while their instantiations, i.e., relational complexes, are concrete.

We argued in section 4 that the realist about universals can best tackle the location

problem by replacing Russellian property universals with monadic tropes that are instances of property kind universals. On this account, instantiation is considered a primitive formal ontological relation connecting abstract property universals and their concrete instances (tropes). As a consequence, the realist avoids the location problem because universals do not stand in any other formal relation to their instances. On the other hand, the formal relation of characterisation between monadic tropes and objects is less problematic than relational inherence, on which the Russellian must rely. Thus, in order to give a satisfactory account of the instantiations of properties, realists with respect to universals are strongly recommended to postulate tropes, and the best available view introduces monadic property tropes. Although the resulting position closely resembles the Neo-Aristotelian four- or six-category ontologies (Lowe 1998, 2006, 2009; Ellis 2001), the further primitive categories of the Neo-Aristotelian schemes (e.g., substantial kind universals, processes, dynamic kind universals) need an independent motivation.

\section{References}

Armstrong, D.M. (1978): Nominalism and Realism, Universals and Scientific Realism vol.1, Cambridge, Cambridge University Press.

Armstrong, D.M. (1989): Universals - an Opinionated Introduction, Boulder, Westview Press. Armstrong, D.M. (1997): The World States of Affairs, Cambridge, Cambridge University Press. Armstrong, D.M. 2004: Truth and Truthmakers, Cambridge, Cambridge University Press. Bergmann, G. (1967): Realism - a Critique of Brentano and Meinong, Madison, The University of Wisconsin Press.

Berman, S. (2008): "Universals: Ways or Things", Metaphysica 9 (2), 219-234.

Betti, A. (2014): "Against Facts", manuscript. 
Bonini, G (2009): "Space, time, concrete, abstract", in Gustav Bergman - Phenomenological Realism and Dialectical Ontology, ed. by B. Langlet and J-M. Monnoyer, Frankfurt: ontos verlag, 69-86.

Bradley, F.H. (1897): Appearance and Reality (second edition, first edition 1893). London, George Allen \& Unwin.

Correia, F. \& Keller, P. (2004): "Introduction", Dialectica 58(3), 275-278.

David, M. (2013): "The Correspondence Theory of Truth", The Stanford Encyclopedia of Philosophy (Fall 2013 Edition), Edward N. Zalta (ed.), URL = <http://plato.stanford.edu/archives/fall2013/entries/truth-correspondence/

Dodd, J. (1999): "Farewell to States of Affairs", Australasian Journal of Philosophy 77 (2), 146-160.

Ehring, D. (2002): "Spatial Relations Between Universals", Australasian Journal of Philosophy 80(1), 17-23.

Ellis, B. (2001): Scientific Essentialism, Cambridge, Cambridge University Press.

Gilmore, C. (2003): "In Defence of Spatially Related Universals", Australasian Journal of Philosophy 81(3), 420-428.

Hochberg, H. (1978): Thought, Fact, and Reference: The Origins and Ontology of Logical Atomism, Minneapolis, MN, University of Minnesota Press.

Hochberg, H. (2009): "Facts and Things", in States of Affairs, ed. by M.E. Reicher, Frankfurt, ontos verlag, 83-110.

Lowe, E.J. (1998): The Possibility of Metaphysics, Oxford, Oxford University Press.

Lowe, E.J. (2006): The Four-Category Ontology, Oxford, Oxford University Press.

Lowe E.J. (2009): More Kinds of Being, Oxford, Wiley-Blackwell.

Lowe E.J. (2013): "In Defence of Substantial Universals", a manuscript of the paper presented at the Conference on The Problem of Universals in Contemporary Philosophy, Scuola Normale Superiore, July 2010, Pisa.

MacBride, F. (2011): "Relations and Truthmaking", Proceedings of the Aristotelian Society $111(1 \mathrm{pt} 1), 161-179$. 
Maurin, A.-S. (2002): If Tropes, Dordrecht, Kluwer Academic Publishers.

Maurin, A.-S. (2010): "Trope Theory and the Bradley Regress", Synthese, 175(3): 311-326.

Maurin, A.-S. (2012): “Bradley’s Regress”, Philosophy Compass 7(11), 794-807.

Moreland, J.P. (1985): Universals, Qualities and Quality Instances - a Defence of Realism, Boston, University Press of America.

Moreland, J.P. (2001): Universals, London, McGill-Queen's University Press.

Noonan, H. \& Curtis, B, (2014): "Identity", The Stanford Encyclopedia of Philosophy

(Summer 2014 Edition), Edward N. Zalta (ed.), URL =

<http://plato.stanford.edu/archives/sum2014/entries/identity/>

Parsons, J. (2007): "Theories of Location", Oxford Studies in Metaphysics vol 3, D.W. Zimmerman (ed.), 201-232.

Paul, L.A. (2002): "Logical Parts", Nous 36 (4), 578-596.

Rodriguez-Pereyra, G. (2004): "The Bundle Theory is Compatible with Distinct but Indiscernible Particulars", Analysis 64(1), 72-81.

Simons, P.M. (1987): Parts: A Study in Ontology, Oxford, Clarendon Press.

Simons, P. M. (2003): “Tropes, Relational”, Conceptus 35, 53-73.

Smith, B. (1997): "On Substance, Accidents and Universals", Philosophical Papers 27 105127.

Smith, B. \& Mulligan, K. (1983): "Framework for Formal Ontology", Topoi 2, 73-85.

Tugby, M. (2013): "Platonic Dispositionalism", Mind 122 (486), 451-480.

Vallicella, W. (2002): "Realism, Monism, and the Vindication of Bradley's Regress", Dialectica 56(1), 3-35.

Van Cleve, J: (1985): "Three Versions of the Bundle Theory", Philosophical Studies 47(1), 95107.

van Inwagen, P. (1990): Material Beings, Ithaca, Cornell University Press.

Wieland, J-W \& Betti, A. (2008): "Relata-specific Relations: A Response to Vallicella", Dialectica 62(4), 509-524. 